\title{
La enseñanza de la Historia del Cercano Oriente Antiguo: Repensando las categorías de tiempo, espacio y cultura
}

\author{
Horacio Miguel Hernán Zapata' \\ Recibido: 5 de septiembre de 2016 - Aceptado: 14 de octubre de 2016
}

\begin{abstract}
Resumen
Las distintas dimensiones de la vida histórica, el tiempo, el espacio y la cultura, son el resultado de operaciones analíticas a través de las cuales se parcela una realidad única e indivisible en los hechos para procurar comprenderla. Sin embargo, tal parcelamiento en el sistema educativo conlleva a la organización de cursos y disciplinas que, en el caso de las Ciencias Sociales, obstaculiza la formación de un pensamiento complejo, autónomo, crítico y reflexivo en los estudiantes. Por ello, es preciso implementar el recorte y abordaje de problemas que posibiliten analizar a las diferentes sociedades de manera compleja e integrada. El artículo tiene el propósito de revisar críticamente las categorías de tiempo, espacio y cultura en la enseñanza de la historia de las sociedades del Cercano Oriente antiguo, deconstruir los supuestos básicos subyacentes de los moldes epistemológicos empleados y redefinir los puntos básicos desde los cuales se parte al enseñar dinámicas sociohistóricas que tienen lugar en otras coordenadas espacio-temporales.
\end{abstract}

Palabras clave: Enseñanza, Historia del Cercano Oriente Antiguo, Tiempo, Espacio, Cultura.

\section{Teaching the History of the Near East: Rethinking the Categories of Time, Space and Culture}

\begin{abstract}
The different dimensions of historical life, time, space and culture are the result of analytical operations through which a unique and indivisible in the facts reality is divided, in an effort to understand it. However, such division in the educational system entails the organization of courses and disciplines that, in the case of Social Sciences, hinders the formation of a complex, autonomous, critical and reflective thinking in students. Therefore, it is ne-
\end{abstract}

1 Argentino. Docente-Investigador de la Universidad Nacional del Chaco Austral (UNCAus), de la Universidad Nacional del Nordeste (UNNE) y del Instituto Superior de Formación Docente "Profesor Agustín Gómez" (ISFDPAG). E-mail: horazapatajotinsky@hotmail.com 
cessary to implement the reduction and approach of problems that make it possible to analyze the different societies in a complex and integrated way. The article aims to critically review the categories of time, space and culture in the teaching of the history of ancient Near East societies, to deconstruct the underlying basic assumptions of the epistemological molds used, and to redefine the basic points from which to begin the teaching of sociohistorical dynamics that take place in other spatial-temporal coordinates.

Keywords: Teaching, History of the Near East, Time, Space, Culture.

\section{0 ensino da História do Antigo Oriente Próximo: Repensar as categorias de tempo, espaço e cultura}

\section{Resumo}

As diferentes dimensões da vida histórica, tempo, espaço e cultura, são 0 resultado de operaçõos analíticas, através das quais parcela-se uma realidade única e indivisível nos fatos para tentar compreendê-la. No entanto, tal parcelamento no sistema educativo leva a organização de cursos e disciplinas que, no caso de Ciências Sociais, impede a formação de um pensamento complexo, autônomo, crítico e reflexivo nos estudantes. Portanto, é preciso realizar o recorte e abordagem de problemas que façam possível analisar as diferentes sociedades de forma complexa e integrada. 0 artigo tem como objetivo rever criticamente as categorias de tempo, espaço e cultura no ensino da história das sociedades do Antigo Oriente Próximo, desconstruir os supostos básicos subjacente dos moldes epistemológicos utilizados e redefinir os pontos básicos desde onde começa o ensino de dinâmicas sócio - históricas que tem lugar em outras coordenadas espaço-temporais.

Palavras-chave: Ensino, História do Antigo Oriente Próximo, Tempo, Espaço, Cultura.

El ser conscientes de los fundamentos conceptuales nos ayuda a ver más allá de lo que fue hecho y lo que está siendo hecho para

llegar a lo que podría hacerse, a lo que una disciplina permite más allá de las prácticas particulares de sus exponentes pasados y presentes (Megill, 1993: 72)

La realidad social constituye ese conjunto de las relaciones complejas, dinámicas y contradictorias que el hombre construye socialmente en un espacio particular a lo largo del tiempo y que se manifiesta tanto en una dimensión material (un modo de producción configurado a partir de la interacción con la naturaleza) como en una dimensión simbólica (un sistema de representaciones construido a partir de las imágenes que las sociedades tienen de sí mismas y de las demás). Dentro de este proceso, los sujetos sociales tienen capacidad de acción y decisión a través de los múltiples vínculos que establecen entre 
sí, expresados en conflictos y consensos. En la configuración de esa realidad social, se va plasmando al mismo tiempo y de manera casi imperceptible la "vida histórica" de una sociedad, coexistiendo elementos del pasado (continuidades) con otros nuevos (cambios) que hacen a las intencionalidades y necesidades de la comunidad que la produce. Además, debe considerarse que las relaciones sociales son modeladoras de la espacialidad humana, es decir, son el componente esencial en la construcción, modificación y aun transformación del espacio geográfico. Contrariando las representaciones de espacio inerte o muerto, o las de territorio meramente como escenario, el espacio constituye un ambiente construido desde lo humano y que, en su conformación según determinadas relaciones sociales de producción y poder, también ayuda a edificar lo que es la cultura, afectando de modo diferenciado y desigual la vida social de grupos, clases sociales y pueblos durante la historia. Finalmente, a lo largo del tiempo y sobre ese espacio va construyéndose la cultura. Los seres humanos vivimos la realidad como esa totalidad armónica a la vez que conflictiva y nuestras acciones no son lineales ni se ciñen a un campo específico de lo social. Por el contrario, nuestras prácticas no se producen exclusivamente en el espacio, en la cultura o en el tiempo sino que atraviesan todas estas dimensiones y producen transformaciones que se retroalimentan entre sí.

Sin embargo, en muchos de los actuales sistemas escolares -incluidos los de América Latina-, la Educación Media, Secundaria o Preparatoria se encuentra organizada en materias, asignaturas o cursos que, en el caso de las Ciencias Sociales, responden a una lógica disciplinar de raíz decimonónica: Historia, Geografía, Formación Ética y Ciudadana, Filosofía, Sociología, Economía, entre otras "sociales o humanidades". Como resultado, no solo se parcelan los saberes y disocian los enfoques, sino que además -y especialmente- se obstaculiza la formación de estudiantes reflexivos, autónomos, críticos, con un manejo amplio y profundo conocimiento de los hechos, fenómenos y procesos sociales más significativos de las sociedades, del pasado y del presente, que les permita revisar sus propias visiones y tomar posiciones argumentadas sobre una serie de cuestiones que son materia de interés y preocupación de la ciudadanía en general. Si uno de los principales propósitos que persigue la enseñanza de las Ciencias Sociales en la educación media o secundaria es, justamente, incentivar que los estudiantes desarrollen ese pensamiento crítico y reflexivo sobre su realidad, es preciso que los profesores de Historia, Geografía y Educación Cívica implementen, dentro de las muchas estrategias pedagógico-didácticas posibles, el recorte y abordaje de problemas que posibiliten analizar a las diferentes sociedades de manera compleja e integrada, como una totalidad sistémica. Por lo tanto, resituar el abordaje de las distintas dimensiones desde las que puede comprenderse la vida social en función de ciertas temáticas, constituye un ejercicio que posibilita formular un pensamiento crítico e integrado de lo social. 
En consecuencia, es preciso partir de la premisa de que las distintas dimensiones de la vida histórica, el tiempo, el espacio y la cultura, son el resultado de operaciones analíticas a través de las cuales los investigadores parcelan una realidad única e indivisible en los hechos y, de ese modo, procuran comprenderla en toda su especificidad, captando y profundizando el estudio de algunos de sus aspectos. En efecto, tales dimensiones no son autónomas y están íntimamente conectadas. Con el objeto de contribuir a las prácticas educativas, el presente artículo tiene el propósito de revisar críticamente las categorías de tiempo, espacio y cultura en la enseñanza de la historia de las sociedades del Cercano Oriente antiguo. Hemos escogido esta problemática porque, además de ser objeto de nuestra especialidad académica, es harto conocido que en muchos de los sistemas educativos, incluidos los de América Latina, aún hoy, la secuenciación y tratamiento de los contenidos históricos en los currículos escolares determinan un abordaje de los eventos y procesos acontecidos a lo largo de la Historia desde los parámetros sintomáticos de la experiencia moderna occidental. En consecuencia, la historia de las sociedades del antiguo Cercano Oriente que es enseñada es, en buena medida, tributaria de una visión histórica asentada en una antropología eurocéntrica, una periodización evolucionista y una metodología historiográfica positivista. Sin embargo, a la luz de los debates cruciales en torno a la presencia de nuevos paradigmas pedagógicos, particularmente aquellos que nos invitan a formar a nuestros estudiantes como futuros ciudadanos capaces de convivir en una realidad cada vez más intercultural y globalizada, nos desafían inevitablemente a abordar viejos temas desde una diferente y renovada posición historiográfica y epistemológica. Una historiografía que nos proponga una relectura crítica del discurso eurocéntrico que moldeó las reflexiones, del empleo monopólico de ciertas categorías y de las operaciones epistémicas por las que Occidente se afirma en su papel históricamente hegemónico. Una historiografía de la alteridad que nos exige continuamente el replanteo acerca de quiénes eran esos otros del pasado y quiénes somos, también, nosotros en el presente, enseñándonos que la otredad es el producto de una construcción histórica (Pfoh, 2007a; Murphy, 2013; Zapata, 2015).

En ese sentido, para comprender la especificidad de los modos de vida y organización que se configuraron en el Cercano Oriente durante la época antigua debemos efectuar una revisión -y reajuste crítico- de su tradicional encuadre espacio-temporal y caracterización socio-antropológica a partir de las tradiciones y categorías historiográficas que hemos heredado dentro de la cultura escolar. Consideramos que analizar estas cuestiones resulta una empresa de sumo interés para deconstruir los "supuestos básicos subyacentes" (Gouldner, 1979 [970]) de los moldes epistemológicos empleados y redefinir los puntos básicos desde los cuales partimos cuando decimos enseñar las dinámicas sociohistóricas que tienen lugar en otras coordenadas espacio-temporales. 


\section{El tiempo: del paradigma de Ex Orient Lux a la multiplicidad de "amaneceres" en la historia}

En tanto nuestra perspectiva de análisis proviene de la Historia, la cuestión del tiempo es la primera variable que debemos examinar. La problemática de la periodización, esencial en el análisis y estudio de los procesos sociohistóricos, presenta serios problemas en relación a la forma de pensar las sociedades orientales, su historicidad y, particularmente, su significado dentro de la historia general. Como es sabido, el "cuadripartismo histórico" -modalidad de periodificar el proceso histórico en cuatro grandes "Edades" (Antigua, Medieval, Moderna y Contemporánea)- continúa siendo importante en los esquemas de historia universal empleados en las escuelas y universidades, importancia que se deriva de lo que podría denominarse, en forma burda, un "potencial didáctico" que posibilita ordenar y clasificar las sociedades concretas y facilita el estudio de forma particular y general (Castellán, 1958: 15-18; Murphy, 2013: 178-179). De ahí que la misma mantenga el consenso en los ambientes académicos, aunque esta aparente ventaja no nos debe hacer olvidar que como toda convención, es sumamente discutible y más aún si, fundamentándose en la utilidad pedagógica, se sacrifica la complejidad en beneficio de la superficialidad. ${ }^{2}$ Dentro de la misma, todos aquellos hechos relacionados con el "origen de la civilización" que tenían lugar en espacios y tiempos diversos y remotos, pero resultaban imposibles de sincronizar cronológicamente, fueron depositados en una única entidad cronológica: la "Antigüedad", la cual no correspondía a la idea de una "edad antigua", es decir, de una historia antigua del mundo. ${ }^{3}$ Sin embargo, esa misma Edad

2 Ciertos señalamientos críticos, como el hecho de ser demasiado eurocéntrica, de dejar la sensación de que el devenir histórico se desarrolló con líneas de ruptura puntuales y nítidas y de encerrar los hechos del pasado en intervalos temporales sin conexión, nos muestran que esta periodización no está exenta de limitaciones como herramienta para hacer comprender realmente los procesos históricos (Chesneaux, 2005 [1976]: 97-105; González y Porta, 1997).

3 El concepto de Antigüedad constituye, en principio, la proyección de los fragmentos de una memoria que una sociedad conserva acerca de una época precedente y que considera una instancia clave en su formación como cultura histórica, esto es, como aquel pasado en que una comunidad encuentra sus orígenes y sus miembros se referencian de modo colectivo, al punto de constituir una tradición común. En este sentido, Ángel Castellán afirma que “... la antigüedad es para cada complejo cultural, la cultura madre antecedente, algunos de cuyos elementos, trasvasados y reelaborados, se proyectan en nuevas direcciones en los productos de la cultura-hija" (citado en Murphy, 2013: 180). En efecto, la noción de historia antigua derivaba, como ha planteado el historiador brasileño Norberto Luiz Guarinello, de una percepción subjetiva de quienes, desde temprano y en Europa, se interesaron por las referencias a un pasado antiguo que proporcionaban diversas instituciones políticas, prácticas culturales, obras literarias y demás objetos materiales, un imaginario del mundo de antaño ya superado pero que continuaba latente. En efecto, la idea de la existencia de una Historia Antigua fue desarrollada por los pensadores del Renacimiento. Presuponía, al mismo tiempo, una ruptura y una recuperación, religiosa y cultural, entre dos mundos. 
Antigua no tenía una coherencia interna, más allá del hecho de que contenía todo lo anterior al advenimiento del medioevo. Debido a que abarcaba muchos milenios y diversas culturas, pronto los historiadores decidieron subdividir esa edad en dos "fases": una "Antigüedad Clásica", más próxima para la cultura europea en una clave espacio-temporal, y una "Antigüedad Oriental", más alejada en estos mismos términos, pero más específicamente en una dimensión político-cultural. A partir de ejes llamativamente similares, otra nueva subdivisión procedería a parcelar esa "Antigüedad Oriental" en dos historias yuxtapuestas: por un lado, una historia antigua del "Cercano Oriente" y, por el otro, una historia antigua del "Lejano Oriente".

Por cierto, es indudable que los criterios que organizaron de tal manera el pasado han estado permeados por un profundo etnocentrismo, el cual ha promovido y difundido dentro de las tradiciones académicas en el área de los estudios antiguo-orientales más reputadas a nivel mundial, inclusive en aquella fundada tempranamente en nuestro país, una suerte de enfoque historiográfico que, cual si fuera un dictum, fija arbitrariamente la política científica de considerar únicamente las experiencias históricas que se conectan más directamente con las de Occidente. En ese sentido, el punto de partida de tal modelo procedía de la valorización de un Cercano Oriente, por cuanto era ambivalentemente apreciado por el Occidente en tanto "cuna de la civilización" y espejo invertido, frente al desinterés "legitimo" que despertaba la tarea de indagar en el pasado de un Lejano Oriente, un mundo mucho más misterioso y exótico, pero más que nada, un universo más distante y ajeno.

Por un lado, constituye un lugar común en la enseñanza de la historia la utilización del modelo interpretativo del "mito de los orígenes" a partir del cual el Cercano Oriente antiguo es concebido como la "cuna" o el "alba de la civilización". Vale recordar que este paradigma conceptual tuvo sus primeras expresiones en la preocupación cultural y política de las sociedades europeas a fines del siglo XIX por evocar un pasado lo suficientemente pródigo como para reconocer en éste los orígenes histórico-culturales de la sociedad occidental. Y basado en esa misma lógica se ha reproducido dentro de los diseños curriculares como verdadero en un modelo pedagógico que posibilitaría rastrear los supuestos antecedentes de los caracteres constitutivos de Occidente. Según este modelo, Cercano Oriente representaba el despertar de todos aquellos elementos que Occidente consideraba relevantes dentro de la historia de la hu-

Una ruptura que daba un cierto sentido a la historia, como la recuperación de algo perdido, como la restauración de un lazo que había sido quebrado durante la así llamada Historia del Medio, la Historia Medieval. De este modo, se asociaba su mundo contemporáneo, la Europa de los siglos XV y XVI, con un cierto pasado. Para los hombres de ese tiempo, era la Historia Antigua de su mundo. De hecho, la propia idea de historia antigua representa una visión europea de historia, un cierto modo de considerar la historia mundial desde una perspectiva occidental (Guarinello, 2003: 51; 2013: 17-28). 
manidad (como el Estado, la escritura, las ciudades, las religiones monoteístas, el arte y las ciencias), pero en ningún sentido constituían su mayor realización o culminación. En consecuencia, representaba un trasfondo arquetípico que, empleando las metáforas biologicistas u organicistas de la época, abrigaba las bases "embrionarias" de la historia del hombre y de la cultura. Aun así, el desarrollo y perfeccionamiento de todos los atributos que se estimaban trascendentes se encontraban naturalmente expresadas bajo formas "adultas" y "superiores" en Europa y, más tarde, en Estados Unidos. En efecto, al amparo de estos esquemas evolucionistas del desarrollo social y cultural, así como también de la idea decimonónica del progreso, la historia del Cercano Oriente antiguo fue traducida como el "punto de partida" de una prolongada trayectoria lineal, ascendente y direccionada cada vez más al poniente: la democracia griega, el imperio romano, la Europa medieval cristiana, el Renacimiento, la modernidad ilustrada y el mundo contemporáneo. Inmersas en el curso de esa secuencia histórica, las instituciones, el conocimiento, la tecnología y la cultura eran pasados como si se trataran de una "antorcha" en una carrera de postas y relevos hasta alcanzar su meta final en un Occidente blanco y capitalista, cuyas principales capitales y sociedades metropolitanas eran presentadas como pináculos del progreso y la civilización (Bahrani, 1998, p. 162-163; Liverani, 2012 [1991], p. 19-22; 1999, p. 5).

Por otro lado, no resulta difícil comprobar que las prácticas de enseñanza de la historia continúan reproduciendo otro lugar común, vinculado a la concepción de la antigüedad oriental como antítesis de la antigüedad occidental. A partir de esta premisa afloran pares polares que resultan tópicos o metáforas recurrentes en la explicación que muchas veces brindamos a nuestros estudiantes, entre los cuales sobresalen las oposiciones entre despotismo oriental y la democracia occidental; entre el palacio oriental y la polis griega o civitas romana; entre el inmovilismo tecnológico y cultural de Oriente y el progreso acumulativo de las civilizaciones europeas; entre una sabiduría mística, oculta y mágica de Oriente y la reflexión laica, racional y científica de Occidente. ${ }^{4}$ Fue a partir de estas tesis que el estudio de las civilizaciones del

4 Si bien tales modalidades de no-reconocimiento y estigmatización de la alteridad no-europea puede parecer apenas una deriva de un discurso moderno, es indudable que los principios que cimentaron progresivamente este paradigma de la superioridad occidental -en el cual Oriente pasó a ocupar el "lugar geométrico de los elementos de polaridad respecto al Occidente 'nuestro'" (Liverani, 2012 [1995]: 20)- pueden remontarse al menos a las tradicionales orales del período de la llamada "Edad Oscura" (ca. 1100-800 a. C.), pero con más claridad a las composiciones historiográficas - 0 , con mayor precisión terminológica, cuasi etnográficas- de Heródoto, Polibio, Estrabón, Dionisio de Halicarnaso, Diodoro Sículo, Plutarco y Flavio Arriano, autores oriundos de los universos helénicos, helenísticos y romanos contemporáneos a las civilizaciones orientales en su fase más tardía (West, 1995; Liverani, 1999: 3; 2012 [1995]: 20; Hartog, 1999 [1996]; 2002 [1980]; Gómez Espelosín, 2004; Al-Otaibi, 2006). 
Cercano Oriente fue incluido en los programas de Historia, en la medida en que éstas detentaban el papel de vórtice del cual emanaron los principales elementos que conformarían las bases para el futuro desarrollo de la humanidad. En el marco de ese esquema evolutivo unilineal, los grandes logros culturales y tecnológicos de la historia tienen su temprano nacimiento en Egipto y Mesopotamia y apenas emergen, son "recuperados" por griegos y romanos, quienes son los primeros -aunque no los únicos-en "modificar" y "perfeccionar" ese conjunto de conocimientos y técnicas hasta transformarlos en un verdadero acervo del mundo latino, occidental y cristiano, capaz de ser transmitido y generalizado ampliamente como legado universal.

Frente a la vigencia de este tipo de esquema en la explicación del cambio histórico dentro del ámbito escolar, podemos alzar ciertas objeciones críticas. Se trata de una visión que tiende a otorgar una dirección unitaria y acabada al proceso histórico en su trayectoria hacia el presente. Si bien es cierto que una serie de hechos significativos en la historia de la humanidad (como las primeras manifestaciones de la vida aldeana, la consolidación del patriarcado, el inicio de la urbanización, el surgimiento de Estados, la aparición de la escritura, la formación de los primeros imperios, etc.) han tenido lugar en el Cercano Oriente, aquella visión conduce a plantear el problema de la interpretación de la dinámica histórica desde enfoques evolucionistas y difusionistas (Cervelló Autuori, 1996: 14) y, en consecuencia, a adherirse al postulado de que "... la humanidad se ha lanzado a una carrera mundial en pos del triunfo universal de la razón y los valores occidentales, y que las antiguas costumbres son reemplazadas por otras nuevas y mejores" (Kemp, 1992 [1989]: 13). Así, desde el evolucionismo, las grandes civilizaciones de Egipto y Mesopotamia representaban el primer gran estadio en la historia del progreso humano, en la medida que sus panoramas histórico-culturales mostraban que las tecnologías, las prácticas económicas y los modos de agregación social avanzan desde formas simples y menos desarrolladas hasta otras más complejas y elaboradas. Desde el difusionismo, a su vez, los rasgos culturales más significativos tenían su único origen -exacto en términos cronológicos y espaciales- en esas civilizaciones evolucionadas, a partir de las cuales se dispersaban geográficamente y eran adoptados pasivamente por otras sociedades con menor grado de desarrollo. Este planteo polémico de la influencia directa a partir de un único foco no solo desconsidera, sino que además obstaculiza la identificación de las distintas resignificaciones que las ideas, las prácticas y/o los artefactos experimentan cuando efectivamente son incorporados por una sociedad que no los ha inventado de forma independiente.

Así las cosas, una clave teórica evolucionista se sumaba a otra difusionista con el objeto de explicar la aparición de ciertas creaciones materiales e intelectuales que, para nosotros, forman parte del bagaje normal de los individuos y la sociedad contemporáneos y, a través de este camino, fundamentar la 
significación de los procesos históricos del antiguo Cercano Oriente desde la perspectiva temporal solidaria con el discurso hegemónico de un modelo civilizatorio específico (Cervelló Autuori, 1996: 2). Nos referimos al discurso según el cual hoy, luego de varios siglos de extraordinarias articulaciones dialécticas de saberes y valores, Occidente representa el modelo de vida ideal, universal y globalizado. En efecto, como afirma Marcelo Campagno:

"No hace falta abundar demasiado en detalles para poder advertir que tal versión de la historia, al amparo de una concepción evolucionista aún dominante en la percepción de los procesos sociales, legitima abiertamente la expansión de ese Occidente sobre el resto del planeta, naturalizando su experiencia histórica como la experiencia histórica y jerarquizando las sociedades por su mayor o menor similitud con el decurso de esa experiencia". (Campagno, 2004: 52).

Sin embargo, más allá de las consecuencias teóricas que conlleva esta visión para el análisis de los procesos históricos, sus contenidos también tienen efectos en una importante medida sobre los terrenos actuales de la política y la ideología. En efecto, la expresión más potente y extrema de tales percepciones -especialmente en su expresiones tecnocráticas y neoliberales vigentes en la actualidad- es lo que puede ser descripto literalmente como la naturalización de las relaciones sociales, la noción de acuerdo a la cual las características de una determinada sociedad son la expresión de las tendencias espontáneas y naturales de la evolución histórica. La sociedad moderna occidental se constituye, desde esta perspectiva, no solo en el orden social deseable, sino en el único posible, imponiendo la "falsa coartada" de que la política y el debate son elementos innecesarios, en la medida en que ya no hay alternativas posibles a ese modo de vida. En esta línea, De Bernardi y Ravenna señalan que:

"La pervivencia de esta forma de pensar la Historia demuestra, además, que los viejos prejuicios -propios del paradigma evolucionista del progreso- se resisten a morir y, por el contrario, se ven alentados por un mundo de poder que ha demostrado ser unipolar y por la imposición de un pensamiento único. Cuando los modelos económicos determinan la exclusión social de gran parte de la población de cada país, y de países y continentes enteros del concierto mundial, no es sorprendente la reaparición, solapada o abierta, de posiciones a las que otrora denomináramos eurocéntricas y que ahora con mayor precisión podríamos definir como 'occidentocéntricas', con todo lo cultural e histórico que la noción de Occidente contiene. Esto no solo afecta los alineamientos políticos, sino también el campo académico y científico en general, por el riesgo de que en cualquier momento la autonomía del pensamiento pueda ser interpretada como amenaza a los intereses coyunturales o de largo plazo del poder instituido" (De Bernardi y Ravenna 2006: 25. Traducción nuestra). 
Aunque las hipótesis evolucionista y difusionista han ido perdiendo numerosos adeptos, aún hoy se encuentran muy arraigadas en la cultura académica. Referencias de esta proyección pueden encontrarse, por ejemplo, en las ideas de "sociedades evolucionadas" o de "cultura madre" empleadas en artículos de revistas de divulgación científica o en manuales escolares de historia y ciencias sociales de uso corriente (Preiswerk y Perrot, 1979 [1975]; Liverani, 2003). Independientemente del formato de tales productos, a lo largo de las páginas el mayor peso explicativo recae en la hipótesis de una supuesta evolución de carácter inevitable que experimentan en un determinado momento uno o más centros poblacionales, por lo general localizados en los valles de los ríos Nilo, Tigris y Éufrates, para luego comenzar a operar como "focos de irradiación cultural" hacia otras regiones. En consecuencia, la narración elaborada sobre la historia del antiguo Cercano Oriente, lejos de brindar una clave interpretativa más compleja, asume la forma de una esquemática sinopsis, plagada de errores y lugares comunes, lo que Liverani ha descripto como "una sucesión de invenciones, introducciones de nuevos elementos técnicos y culturales, modos de producción cada vez más eficaces, formaciones políticas cada vez más complejas y expresiones humanas cada vez más libres y elevadas" (Liverani, 2012 [1991]: 728).

No podemos continuar apelando al planteo de que Oriente Próximo constituye la cuna de la civilización occidental, o a la idea de que sus sociedades alcanzaron una evolución cultural de tal magnitud que les permitió difundir sus "adelantos" en múltiples direcciones, como fundamento central de las explicaciones. Hacerlo sería quedar enfrascados, como lo hizo notar Marc Bloch, en la lógica del "ídolo de los orígenes", es decir, en la tendencia a pensar que al hallar los antecedentes temporales de un proceso, descubrimos también los fundamentos que lo explican (Bloch, 2001 [1944]: 59-64). Pero tampoco podemos dejar de reconocer la particular significación de ese Oriente como uno de los tantos y multiformes escenarios históricos que protagonizó el inicio de importantes cambios trascendentales a nivel de la organización socioeconómica y política derivados del asentamiento de la población en comunidades permanentes. Antes bien, tomar conciencia de los prejuicios etnocéntricos y retóricas esencialistas que inducen tales posiciones historiográficas nos debe conducir a repensar el modo en que enseñamos la historia de estos antiguos pueblos de acuerdo con categorías nuevas y desde perspectivas alternativas. Hasta qué punto esas sociedades vivieron esa transformación de forma única o, en todo caso, supieron capitalizar viejas prácticas, es una pregunta crucial.

En este sentido, una propuesta muy interesante y productiva a nivel pedagógico-didáctico para redimensionar el lugar de las sociedades antiguoorientales dentro de la historia general de la humanidad es que los docentes 
desechemos de nuestra caja de herramientas conceptuales la noción de "regularidad" (dictada por algún tipo de legalidad implícita) y comencemos a emplear el concepto de "matrices de experiencia". Esta categoría conceptual, como han puesto de manifiesto De Bernardi y Ravenna, nos permitirá descubrir ciertas correspondencias entre los procesos antiguos y actuales, que aunque tuvieron lugar en distintas geografías y tiempos e implican profundas y enormes diferencias, guardan múltiples puntos en común, tomando conciencia de la posibilidad de penetrar en el campo de las antiguas culturas del Cercano Oriente a partir de ciertos fenómenos que nos atraviesan, como:

"la búsqueda permanente por solucionar el modo de subsistencia; los procesos de intensificación de la producción y el acaparamiento desigual de los excedentes; los fenómenos de diferenciación social concomitantes; la aparición del poder político y el Estado; la estandarización de las relaciones intergrupales y externas; la guerra; el surgimiento de un mundo de representaciones mentales compartidas que da coherencia al grupo; la manipulación de esas representaciones por parte de las élites para transformarlas en símbolos diacríticos identitarios y simbolismos de reforzamiento del poder; los procesos de legitimación de las instituciones que garantizan la reproducción de las condiciones desiguales; para nombrar solo las nervaduras de la trama social." (De Bernardi y Ravenna, 2006: 24).

Con este procedimiento analítico buscamos brindar alternativas teóricometodológicas para la enseñanza de la historia que posibiliten pensar dichas "constantes" a partir de su equivalencia conceptual y de las singularidades que sugieren los contextos específicos. Esas "constantes" pueden ser caracterizadas como "formas simples", según Mario Liverani, en tanto aluden a una especie de "gramática elemental de la historia" y, a la luz de esa excelente metáfora, comprobamos que, dentro de situaciones de aprendizaje áulico, la historia del Próximo Oriente puede constituirse en:

"un muestrario bastante rico y completo de ellas, con la ventaja única de que nos muestra estas formas simples en el proceso de su formación, y más tarde en su despliegue todavía bastante libre de complicaciones. Como se ha dicho al principio, ...es como un 'laboratorio' histórico privilegiado en el que ciertos fenómenos pueden ser estudiados en estado puro (por así decirlo), al no existir las interferencias que dificultan su reconocimiento y análisis en fases más avanzadas de la historia. Las formas simples son más fáciles de descubrir en su estadio inicial y a nivel ingenuo, pero una vez descubiertas es fácil seguirles la pista como elementos de construcciones mucho más sofisticadas." (Liverani, 2012 [1991]: 726-727). 
Precisamos entonces, como docentes, reubicar a ese eslabón "originario" dentro de un contexto más amplio, redimensionar su locación temporal a partir de otras experiencias históricas de forma diacrónica y sincrónica, y, a través de estas estrategias, hacer comprender que una vez que aparecieron en escena ciertos "acontecimientos" (sensu Foucault, 2013 [1971]; Veyne, 1984 [1978]: 4; Campagno, 2002: 79-82), no lo hacen de una vez por todas, sino que siempre varían de acuerdo a la configuración social en la que se producen, escapando de esos enunciados de lo viable y lo inevitable en el decurso histórico. En esta línea, a la luz de los datos existentes, parece indudable que cambios trascendentales tomaron forma en el Próximo Oriente, aunque la gran cantidad de testimonios disponibles en la actualidad viene a subrayar cuán prolongado y complicado fue el proceso. Así pues, como algunos autores sostienen, ya existía un número importante de elementos para el desenvolvimiento a gran escala cuando se estructuraron en la Mesopotamia asiática meridional y en el valle del Nilo las condiciones de posibilidad que condujeron al surgimiento de un nuevo tipo de dinámicas sociopolíticas en estas zonas. De momento da la impresión de que estas dos regiones adoptaron unos conocimientos y técnicas perfeccionadas ya en otros rincones de Oriente Próximo y que, probablemente debido a la existencia de determinadas circunstancias que permanecen en el terreno de las hipótesis, acabaron diferenciándose tanto en su forma de organización como en la dimensión de sus prácticas respecto de esas otras zonas habitadas (Liverani, 2012 [1991], p. 62-94; Kuhrt, 2014 [1995]: 28-29).

\section{El espacio: de los imaginarios cartográficos etnocéntricos a la geografía de la "unidad en la diversidad"}

La necesidad de comprender la compleja realidad de Oriente nos lleva a examinar la segunda dimensión importante del análisis social: el espacio que habitaron las sociedades antiguas y el modo en que éste ha sido delimitado y caracterizado. Por lo general, el área en la que solemos movernos a lo largo de esa historia de muchos milenios corresponde, en grandes líneas, al valle del Nilo, la Mesopotamia asiática, el corredor sirio-palestino, la península anatólica, el golfo pérsico y la península arábiga. Esta macro-región tiene algunos límites bien precisos (el mar Mediterráneo al norte y oeste, el mar Negro al noroeste y el mar Rojo) y otros más imprecisos aunque claramente perceptibles (las estepas del Asia central al norte, el desierto del Sahara al suroeste y el desierto de Arabia al sur). Existe, sin embargo, otro elemento importante a tener en cuenta a la hora de reevaluar la definición espacial del área y que se resume básicamente en la influencia que ha tenido un imaginario etnocéntrico. A lo largo del siglo XX, nos encontramos con una abigarrada superposición de mapas mentales que forman una especie de "palimpsesto" de cartografías constantemente reelaboradas y precisadas al 
ritmo de las investigaciones y de las agendas políticas, pero que conservaban tenues y no tan tenues trazos de la visión anterior.

Así, un primer mapa mental consagraba la idea de Creciente Fértil, categoría acuñada por quien fuera el fundador del Instituto Oriental, el reputado arqueólogo estadounidense James Henry Breasted (1865-1935), para referirse a la región histórica integrada por los territorios del Levante mediterráneo, Mesopotamia y Persia y que, incluyendo Egipto, se asemejaba por su forma a una extensa Luna creciente (Breasted, 1916). Más allá de que sea un eco o no de la mentalidad de los antiguos pobladores de la región, ${ }^{5}$ es un claro ejemplo de una temprana representación cartográfica que proveyó una matriz lo suficientemente aceptable y vigorosa como para brindar no solo una explicación de las interacciones entre ambiente y sociedad desde un enfoque geográfico determinista, sino también para justificar la implementación de programas políticos en la región. En efecto, la noción de "Creciente Fértil" -o, como también suele encontrarse, "Media Luna de las Tierras Fértiles"estuvo conectada con la visión de un pasado cultural grandilocuente dejado por las primeras exploraciones arqueológicas y fue, en ese sentido, empleada como un importante componente discursivo dentro de los diferentes esfuerzos nacionalistas locales de construcción estatal. Por su parte, el término "Oriente Medio", acuñado por los británicos, no estuvo basado estrictamente en consideraciones históricas y culturales, sino que reflejaba los intereses estratégicos de Occidente. Respaldado por instituciones militares y económicas, este concepto devino en una realidad espacial con fuerte performatividad política, ya que incluso fue incorporada por los propios actores políticos de la región. A estos dos conceptos podríamos agregarlas múltiples acepciones del término "Cercano Oriente", ya que su uso comprende valoraciones contradictorias del papel de Egipto y el Asia suroccidental en la formación del

5 Thomas Scheffer señala que "En la antigüedad, sin embargo, el término 'Creciente Fértil' era desconocido. Ningún rey antiguo había aclamado gobernar el 'Creciente Fértil', ni tampoco era capaz de incluso pensar en ese concepto" (Scheffer, 2003: 253. Traducción propia). Sin embargo, tal concepto conlleva implícitamente la carga histórica de un imaginario de la región compartido por ciertos grupos que poblaron la región en la antigüedad. En tal dirección, compartimos el planteo de Mario Liverani que la imagen más poderosa en la historiografía de Oriente Próximo es la proyecta aquel "mapa mental" elaborado por los propios protagonistas de la historia y que "... sigue un esquema de contraposición entre un núcleo y una periferia. El núcleo, el espacio central, está más habitado y civilizado, y su centro ideal es la ciudad (que a su vez gira en torno al templo o al palacio real), rodeada por una llanura de regadío salpicada de aldeas agrícolas. La periferia es la franja que rodea llanuras, de estepa o montaña, con una población más desperdigada e inestable de pastores, fugitivos, bandidos, que poco a poco se difumina hacia el vacío humano de zonas que sólo son útiles como reservas de materias primas: árboles de alto tronco, metales y piedras duras. Estos 'mapas mentales' se pueden encontrar fácilmente en los textos antiguos, como la imagen de un mundo 'en forma de embudo' de Gudea (c. 2100) que sitúa en el centro del mundo a su ciudad de Lagash, y en su centro al templo de Ningirsu" (Liverani, 2012 [1991]: 38). 
mundo mediterráneo antiguo, medieval y moderno, estereotipos románticos e imperialistas acerca de la correspondencia entre el Islam y el desierto, así como también referencias sobre la fertilidad y potencial productivo del área en el pasado frente a la desertificación, erosión del suelo y deforestación que sufre en la actualidad (Scheffler, 2003).

Los diferentes imaginarios cartográficos sobre Oriente sedimentaron sentidos en las percepciones del espacio que además de evocar cierta memoria de un territorio controlado antiguamente por pueblos avanzados, tornaron factible ciertas dinámicas de hegemonía en la geopolítica regional. Pero no debemos pasar por alto el hecho de que las diversas imágenes de ese "otro" espacio que construyeron intelectuales y políticos poseen un denominador común: todas ellas han estado fuertemente apegadas a una vieja delimitación proveniente de la tradición disciplinaria, desarrollada a principios del siglo pasado, para hacer referencia a las tierras situadas al este de Europa. Ahora bien, si aceptamos que la división entre Oriente y Occidente constituye un dato objetivo de la realidad, es necesario que nos preguntemos si ese Oriente engloba únicamente Asia. De ser así, dejaríamos fuera de toda consideración a Egipto, el cual ha sido tradicionalmente incorporado en los estudios del antiguo Oriente como una entidad sociopolítica y cultural única del África antigua y desprovista de vínculos con otras poblaciones contemporáneas que poblaron la región noreste del continente. ¿Y cómo debemos interpretar, según esos parámetros, la fundación de una serie de colonias por parte de los fenicios en las principales costas e islas del mar Mediterráneo occidental o inclusive aquellas establecidas por los griegos en los bordes de Asia Menor durante su expansión? Tales interrogantes no hacen otra cosa que suscitar más críticas y hacer tambalear la supuesta solidez de la perspectiva determinista. Como afirma Cristina De Bernardi,

"Es evidente que tomar como base para una división de la historia la cuestión geográfica es cuanto menos insuficiente. Si el determinismo geográfico hace ya mucho tiempo fue a parar al desván de las teorías sociales, ¿qué circunstancias autorizan a que dividamos la historia en Asia, África, Europa, sin tener en cuenta los elementos propios de la configuración histórica (la compleja integración que constituye su unicidad)? ¿Y qué prejuicio etnocentrista ha llevado a los científicos a imponerle hasta a la realidad física una división que en ella no existe? ¿Acaso podemos darle a Europa el pomposo nombre de continente siendo que morfológicamente es una península del bloque euroasiático?" (De Bernardi, 1987: 525).

La idea de que existe un mundo "occidental" y un mundo "oriental" debe ampararse, antes bien, en el paradigmático planteo de que la humanidad se ordena espacial y horizontalmente en civilizaciones homogéneas, más o menos herméticas y mutuamente inconmensurables, producto del 
supuesto vínculo existente entre territorio, cultura y moral, reforzando así los postulados del fundamentalismo cultural. Tales predicados no solo han obstaculizado la comprensión crítica de los espacios, sociedades y culturas de Oriente, sino que además fueron retomados recientemente por pretendidos análisis racionales para explicar la reorganización de la geopolítica internacional y la codificación de diversos conflictos sociales y bélicos, reintroduciendo el eufemístico concepto de "choque de civilizaciones". ${ }^{6}$ Sin embargo, cuando escrutamos esta tesis desde el discurso historiográfico, es perceptible que constituye el efecto de una representación occidentocéntrica de vieja data, suficientemente arraigada en el imaginario colectivo como para no notar su constante actualización a comienzos de este milenio. ${ }^{7}$ Resulta ser

6 Mientras que el concepto moderno de civilización es popularizado por Oswald Spengler en sus dos volúmenes La decadencia de Occidente (1922), la noción de "choque de civilizaciones" fue introducida por Arnold J. Toynbee a partir de su gran colección de Estudio de la Historia (1955), aunque éste la restringe al ámbito geopolítico, simplificando los fenómenos de contactos culturales entre civilizaciones. Toynbee considera el fenómeno como un "contacto espacial entre civilizaciones", y lo refiere como un fenómeno de desafío y respuesta: el primer "empujón" que una civilización da a otra, es contestado por ésta, lo que a su vez mueve a la primera a enviar un tercer empujón, y así sucesivamente hasta que una de ellas termina derrotada. En un artículo publicado en la revista Foreign Affairs de 1993, Samuel Huntington retoma el concepto de Toynbee afirmando que los actores políticos principales del siglo XXI serían las civilizaciones y que los principales enfrentamientos serían los "conflictos entre civilizaciones", y no entre Estados-nación, ideologías políticas o sistemas económicos, como lo fue durante la mayor parte del siglo XX. Más tarde amplió sus argumentos en un libro que tituló El choque de las civilizaciones y la reconfiguración del orden mundial (2004 [1996]), una obra que, desde el momento de su difusión, ha recibido críticas desde múltiples ángulos. Acerca de las diferentes respuestas críticas a la tesis formulada por Huntington, cf. Said (1998) y Sardar (2004 [1999]: 148).

7 Es un hecho conocido que el ataque terrorista a las Torres Gemelas -denominado el atentado del 11-9- y la respuesta estadounidense -la invasión político-militar a Irak- produjeron un escenario que renovó estas imágenes ya profundamente arraigadas. La antigua oposición entre civilización occidental (representada por la democracia y el "estilo de vida estadounidense") y barbarie oriental (personificada por Osama Bin Laden y el Islam) recuperó sus bríos y exacerbó el conjunto de acciones que ponían de manifiesto que se trataba de un enfrentamiento absoluto entre nosotros y los otros. Otro de los acontecimientos que ocupó el centro de la escena mundial y actualizó la problemática fue el atentado reaccionario perpetrado en las oficinas del semanario satírico parisino Charlie Hebdo, un acto brutal y criminal sin justificación alguna, condenado por la opinión internacional. Se trató de otro nuevo suceso que concitó múltiples interrogantes sobre lo que está implicado en el mismo, sobre su contexto y precedentes, así como también sobre su impacto directo en la sociedad francesa y sus repercusiones futuras a nivel global. En las distintas respuestas, forjadas en un espacio determinado -París, la gran metrópolis política y cultural de Europa-, sus productores hicieron valer diagnósticos contrapuestos sobre los problemas políticos y éticos que acarrea inexcusablemente el respeto y la defensa de la "libertad de expresión" y "libertad de conciencia". Las posiciones fueron polarizándose aún más cuando salió a la luz el hecho de que la comunidad islámica -una de las mayores comunidades religiosas de Europa-, aquella señalada por la opinión mayoritaria como única responsable del atentado, haya sido una de las primeras colectividades confesionales que se solidarizara y manifestara en contra de esta tragedia a pesar de haber sido sistemáticamente humillada por la línea editorial de esta publicación a lo largo de los años. Las diversas percepciones articuladas 
apenas la "punta del iceberg" de ese largo, complejo, híbrido y sinuoso proceso de construcción social que Edward Said estudió en su libro Orientalismo. La conclusión a la que arribaba este autor es que el orientalismo constituye "un discurso que habilita una disciplina sistemática a través de la cual la cultura europea ha sido capaz de manipular -e incluso de dirigir- a Oriente desde un punto de vista político, militar, sociológico, ideológico, científico e imaginario" (Said, 1990 [1978]: 21). Aunque simple y breve, esta definición nos posibilita comprender que Oriente no es una realidad dada, natural y objetiva, que simplemente está allí, sino que se trata de una entidad tanto geográfica como cultural e histórica, que permite definir, en el contraste, la imagen, personalidad y experiencia de Occidente (Goody, 1996; Lockman, 2004; Sardar, 2004 [1999]; Said, 2005; Murphy, 2006).

A través de una serie de procesos históricos, juegos de poder y jerarquías axiomáticas, Europa y más tarde Estados Unidos imaginaron fronteras fijas y delimitadas que escindían a dos mundos homogéneos en su interior. La construcción de la idea de un mundo del Cercano Oriente interiormente homogéneo y sin fracturas es parte de la construcción de la idea de Occidente $y$, en consecuencia, de la propia gestación de un paradigma dentro de los estudios antiguo-orientales. De este modo, la tradición académica lograba producir -al menos desde el discurso- un Oriente propio, cercano a la civilización occidental y uniformizado tanto en términos geográficos como culturales (Larsen, 1987). Sin embargo, esa uniformidad imaginaria acarrea importantes limitaciones para la enseñanza de problemas históricos de hondas raíces y relevancia actual. No solo hace pasar por alto las características internas de un marco geográfico y ecológico tan extenso como diverso, obstaculizando en esta dirección la reflexión sobre sus implicancias en las estrategias y modos de vida configurados por el hombre a lo largo de la historia para adaptarse a un medio a veces hostil y, al mismo tiempo, al impacto de las acciones humanas sobre el ambiente y los recursos. Dicho constructo conceptual también conlleva la simplificación de la propia dinámica sociohistórica, especialmente en lo que se refiere a las antiguas esferas de contacto y redes de interacción que articulaban internamente la macro-región y externamente con otros espacios, al subrayar los vínculos con determinadas zonas e invisibilizar -hasta lo inimaginable- la existencia de otros en función de su significación para la experiencia occidental y su escala de valores.

alrededor de este trágico acontecimiento conllevaron la resignificación de viejos estereotipos y prejuicios a través de un discurso islamofóbico, de cuño orientalista, eurocéntrico y racista, que concibe a las comunidades de origen árabe y que practican la religión musulmana como poblaciones bárbaras a las cuales hay que controlar, reprimir, oprimir y exterminar (Djait, 1990; Sardar, 2004 [1999]: 41-86; Eco et al., 2005 [2003]; Murphy, 2006; Chérif, 2007). 
El estado actual de las investigaciones cuestiona tales ideas, muy frecuentes dentro de la historiografía, para dejar firmemente asentado que el Cercano Oriente antiguo constituyó un territorio vastísimo y que, como es natural, se caracterizó por una heterogeneidad tanto geográfica como ecológica. A lo largo y ancho de su extensión, relieve, clima, suelo y recursos se distribuyen desigualmente y cambian a veces en distancias muy cortas (Redman, 1990 [1978]: 32-71; Kemp, 1992 [1989]: 16-22; Liverani, 2012 [1991]: 25-27 y 36-42; Kuhrt, 2014 [1995]: 15-18, 21, 33-35, 141-145, 272). Tal diversidad de ambientes incidió en la diversidad cultural, no en el sentido determinista geográfico de la concepción occidentocéntrica sino en aquel proporcionado por los nuevos enfoques. Ante cada ambiente, las comunidades humanas encontraron obstáculos y posibilidades y, para sobrevivir y reproducirse, desarrollaron estrategias y tecnologías específicas, al tiempo que elaboraron múltiples dispositivos culturales y sociales. Además, ese espacio con el cual interactuaron hombres y sociedades también sufrió profundos cambios a lo largo de los milenios en que transcurre la historia. Las comunidades humanas no fueron meras receptoras pasivas de esas mutaciones del entorno físico, sino que actuaban sobre el medio y lo transformaban. En tal dirección, intentando superar sentidos interpretativos que han imperado en la relación entre cultura y ecología, varias investigaciones señalan cómo el medio ambiente no solo obstaculiza de manera negativa la centralización política, sino también puede ofrecer posibilidades positivas para la descentralización social. Además, para analizar este conjunto de cuestiones no podemos recurrir a nuestras concepciones de espacio ni mucho menos plantear la dimensión territorial de los procesos a partir de las circunscripciones políticas y/o administrativas actuales. Debemos ser conscientes de que en el pasado la organización social del espacio y la noción de territorialidad, así como la percepción misma de los paisajes eran distintas de las nuestras (Wilkinson, 2003). Por tanto, es importante transmitir la noción de que -desde tiempos tempranos- cada comunidad en el Cercano Oriente interactuó con su ambiente de una forma específica, lo modificó y recreó para aprovechar mejor sus recursos, de modo que no se trató de un espacio vacío ni poco poblado, al punto de que las áreas no ocupadas eran aquellas donde las condiciones ambientales eran tan extremas que hacían imposible la vida humana.

Del mismo modo, los avances investigativos han permitido comprobar la presencia de un conjunto variado de vínculos que conformaron redes más o menos organizadas de interacciones que resultaban prácticas vitales para la vida social de los grupos del Cercano Oriente antiguo en distintas épocas y lugares, susceptibles de ser recuperadas arqueológica e historiográficamente. Anatolia, Levante y Egipto estuvieron a menudo en contacto directo con el Egeo y, por su parte, Egipto mantuvo durante largos períodos estrechas relaciones con la zona del mar Rojo y el Cuerno de África y también, como se ha sabido muy recientemente y de forma un tanto distante e indirecta, 
con el África subsahariana a través de Sudán (la antigua Nubia). En cuanto a Mesopotamia, y especialmente su parte meridional, tuvo vínculos regulares con el golfo Pérsico y la zona oriental de la península Arábiga. Era ésta la potencial ruta de comunicación entre Mesopotamia y las tierras lejanas del valle del Indo. Los contactos entre las distintas comunidades humanas del Cercano Oriente englobaban la circulación de elementos materiales y simbólicos, siendo un aspecto recurrente que la transferencia de conocimientos, tecnologías y artefactos conformaran un único plano de la realidad que a simple vista parece ser económico, pero que de hecho involucra aspectos sociopolíticos, ceremoniales e ideológicos (Smith, 1965; Polanyi et al., 1976 [1957]; Rowlands et al., 1987; Charpin \& Joannes, 1992; Cervelló Autuori, 1996; Daneri Rodrigo, 2001; Cervelló Autuori et al., 2001; Liverani, 2003 [2001]; O'Connors \& Quirke, 2003; Van de Mieroop, 2004; Daneri Rodrigo \& Campagno, 2004; Aubet, 2007; Adams \& Roy, 2007; Di Bennardis et al., 2010).

Si bien es cierto que hubo contactos continuos, permanentes $y$, en ocasiones, muy intensos, cada espacio mantuvo un alto nivel de autonomía con respecto a los demás. Además, a través de esas rutas no solo circularon objetos complementarios o de estatus, sino también individuos, grupos y poblaciones, insertas en disímiles tramas de obligaciones, lealtades, dependencias, subordinaciones y exclusiones. Guerras, alianzas, comercio y otras maneras de establecer contactos interculturales estimularon, a lo largo de la historia, el desplazamiento de varones y mujeres que lo hicieron de manera voluntaria u obligada. Cuando leemos los diferentes aportes del tema, notamos el hecho de que la alta diversidad humana y geográfica del Cercano Oriente antiguo estimuló un complejo y diverso flujo de personas, bienes e información cuya significación se reflejó no solo en lo material y económico, sino en los roles del hombre y la mujer, en la estructuración de experiencias políticas, en la dinámica étnica y aun en la propia visión ideológica que las sociedades elaboraron de sí mismas, de otras culturas y del universo (De Bernardi, 2001; De Bernardi \& Silva Castillo, 2006; Di Bennardis, 2014). Asimismo, la renovación de las miradas ofrece una nueva cantera para redimensionar la historia de los contactos e interacciones en el ámbito mediterráneo, haciendo dialogar las distintas formas en que circularon innovaciones técnicas, modelos organizacionales e imaginarios sociales entre pueblos helenos y orientales a través del espacio común a la vez que diverso (Bernal, 1993 [1987]; Burkert, 2002 [1999], Burkert, 2005 [1987]; Hobson, 2006 [2004]), sin pretensión de establecer nuevos mitos eurocéntricos de origen y proyectando la posibilidad a futuro de concretar una "reconstrucción de una red compleja de interrelaciones, procurando que cubra en tiempo y espacio toda la historia mundial" (Liverani, 1999, p. 8. Traducción nuestra).

Si los argumentos convencionales no logran resistir las críticas de las últimas investigaciones, es claro que la idea del Cercano Oriente antiguo como una 
gran "área geográfica y cultural" resulta un supuesto muy endeble, sino una entelequia artificiosa y caprichosa. En consecuencia, si podemos pensar en algún tipo de unidad para la historia de las sociedades del Próximo Oriente, esta no podrá derivar de una supuesta evolución hacia formas de organización sociopolítica más avanzadas. Dicha unidad solo podrá serlo a título conceptual, esto es, a partir de la posibilidad de considerar como problema histórico la interpretación de espacios y tiempos compartidos por sociedades con modos de vida diferentes, pero afincados en muy intensas relaciones que conectaron a ese conjunto heterogéneo de pueblos y los convirtieron en coproductores de una trama histórica común a la vez que diversa. Como hemos visto anteriormente, los nexos que originaban la coproducción cultural no fueron siempre de la misma naturaleza, ni se dieron por igual en todos los rincones del Cercano Oriente ni, una vez establecidos, se mantuvieron de manera uniforme y permanente. Muy por el contrario, estuvieron ligados a las experiencias que se generaron, fundamentalmente, a partir de los intercambios de bienes; de los desplazamientos transitorios o permanentes de grupos dentro de la región; de los intereses compartidos entre las elites que gobiernan las diferentes entidades políticas; del dominio de unas sociedades sobre otras; y de las relaciones de alianza y/o conflicto. En efecto, los grupos humanos, independientemente de que vivieran en áreas contiguas, se hallaban conectados por un conjunto complejo y heterogéneo de relaciones que sufrieron los vaivenes de los grandes procesos históricos a lo largo de los milenios.

\section{La cultura: de las grandes civilizaciones a la diversidad de experiencias y ontologías sociopolíticas}

El análisis de las distintas formas de vida, organización y experiencias sociohistóricas que explican las características de las sociedades del Cercano Oriente antiguo nos remite, indudablemente, a la problematización de la tercera variable: el concepto "cultura". Una de las mayores dificultades con las que nos encontramos los docentes a la hora de abordar tales situaciones, es que este concepto vertebrador y transversal del área de Ciencias Sociales se encuentra o bien "naturalizado" en el sentido común -como si se tratara de una realidad que siempre estuvo allí, algo inmutable-, o bien asociado a cierta perspectiva evolucionista difícil de desarraigar. En consecuencia, no resulta poco frecuente encontrar la definición de "cultura" asociada a la noción de "civilización", haciendo referencia por lo general a un estado o etapa por la cual pasaron ciertas sociedades, logrando un nivel de complejidad en sus organizaciones y expresiones materiales y simbólicas, además de haber desarrollado centros urbanos complejos. Con semejante criterio, es fácil comprender por qué ciertas elecciones temáticas sobre el desarrollo cultural de los antiguos pueblos del Próximo Oriente resulten preponderantes dentro de los contenidos, como por ejemplo, el énfasis en el estudio de sociedades urbanas 
y estatales en detrimento de otras poblaciones y grupos con modos de vida diversos; la atención puesta en la evolución política de los grandes Estados e imperios, presentando una trayectoria lineal sin tensiones y contradicciones; la preponderancia de una visión desde arriba, en el sentido de una atención centrada en la vida y hazañas de los grandes hombres mientras que al resto de la sociedad se le asignaba un papel menor en el drama de la historia; la presentación de la historia como narración de acontecimientos y hechos, separando las diferentes dimensiones de la realidad (economía, sociedad, cultura, ideología) en compartimentos estancos y sin conexión; el tratamiento de las creaciones en materia tecnológica, científica, arquitectónica, artística y religiosa como prueba de su avanzada evolución cultural, relevando aquellos legados que se encontraban en la raíz de los logros de todas las épocas; una reconstrucción basada únicamente en sociedades que desarrollaron formas de registro escrito, estableciendo a la escritura como criterio fundante de lo "histórico", descartando del análisis ciertos períodos bajo la denominación de "tiempos prehistóricos" y "edades oscuras". En tal dirección, aquella definición que aprendimos en la escuela, de que la historia humana comienza con el origen de la escritura y de la civilización, es una metáfora que resume de forma clara y directa esta prejuiciosa concepción.

Es bastante común que dichas miradas, aunque se piensen superadas, continúen estando presentes -e incluso quizás sean influyentes- como los fundamentos epistemológicos a los que se aferran docentes y estudiantes siempre que quieren parecer rigurosos a nivel conceptual y metodológico, cuando se trata de ordenar e interpretar los hechos y procesos históricos que tuvieron lugar en aquellas coordenadas espacio-temporales. El propio sistema educacional tiende a reproducirlas de modo inconsciente y casi por inercia, tomándolas como cuestiones de simple tecnicismo académico y naturalizando su influencia en las interpretaciones del mundo histórico. Se trata de una cuestión no siempre advertida y problematizada, ya que somos conscientes de que alterar las formas no constituye una tarea fácil. Nada fácil, pero necesaria y -de algún modo- urgente debido a que las implicaciones y restricciones que acarrean tales perspectivas, las cuales en la superficie pudieran representar meros matices de carácter historiográfico o narrativo, son de suma importancia por su fuerte contenido ideológico y político.

En la atomización del conocimiento que impusieron los enfoques evolucionistas y positivistas, solo ciertas sociedades fueron tomadas en consideración dentro de los programas escolares, siempre en el marco de la búsqueda de las raíces de la cultura occidental o como telón de fondo de importantes fenómenos históricos que significaron la incorporación plena y definitiva de Oriente en entidades políticas de escala suprarregional (Cervelló Autuori, 1996: 15). En efecto, si revisamos los programas escolares, será sencillo notar la influencia del viejo paradigma eurocéntrico en la delimitación del 
concepto de cultura que subyace al abordaje de los problemas, lo que -a su vez- ha conllevado a una descripción insuficiente de las sociedades antiguas del Próximo Oriente y, en numerosos casos, a la exclusión de varias de ellas en materia de enseñanza, que por ser consideradas "irrelevantes", no solo se quedan sin lógica explicativa, sino también y directamente fuera de la historia, relegadas al silencio y al olvido. En efecto, existe una preferencia por estudiar aquellas sociedades que configuraron sofisticadas estructuras en torno a Estados de vasta extensión territorial y dominio político sobre etnias diversas, que dieron lugar a economías excedentarias caracterizadas por el autoabastecimiento, la producción y el intercambio de productos, y que inventaron complejos sistemas de escritura; en suma, aquellas que crearon grandes "civilizaciones". Mientras tanto, aquellas sociedades que no encajaban en esos parámetros por tratarse de poblaciones ágrafas, que poseían organizaciones sociopolíticas no estatales y llevaban estilos de vida nómade, quedaron dentro de la categoría de pueblos primitivos, a los cuales se asociaron además los calificativos de "salvajes" o "bárbaros". ${ }^{8}$

Pero esto no debe ser un motivo para que nos sumemos a la obsesión historiográfica, tan frecuente en los estudios del antiguo Oriente, de exaltar únicamente las obras y las acciones de las sociedades estatales, y de sus elites gobernantes, y de menospreciar otro tipo de organizaciones humanas y otros actores sociales y étnicos de los ámbitos rurales y de frontera. Por el contrario, hoy las cosas han cambiado y, junto con ellas, las perspectivas analíticas. Por un lado, es necesario evitar la apreciación errónea de que la importancia histórica de una sociedad es proporcional a sus logros culturales o a su forma de organización sociopolítica. Cuando se piensa bajo esos parámetros, en el fondo se está sosteniendo que existen un conjunto de cualidades que permiten medir la inteligencia de los individuos de una sociedad y, con ello, determinar si se corresponde o no al desarrollo intelectual y moral de una civilización, concibiendo a esta última como el producto de una mentalidad superior y reviviendo las ideas evolucionistas que hemos criticado. Además, es un hecho muy grave a nivel ético pensar que existen grupos humanos inferiores a otros, por el simple hecho de no compartir las mismas formas de gobierno, creencias religiosas y estilos de vida, y que, en virtud de éstas, puedan ser objeto de burlas y humillaciones, cuando no de olvido. En rigor de verdad, debemos aceptar el hecho de que el tan mentado progreso no nos ha vuelto seres superiores y, en consecuencia, los hombres que vivieron

8 Sin embargo, somos conscientes de que no es posible explicar la preferencia por las altas culturas invocando únicamente razones de índole ideológica. Existe otro tipo de condicionamientos para reconstruir ciertos agentes y situaciones de la realidad histórica que provienen de la información disponible y proporcionada por los propios testimonios con que trabajan arqueólogos e historiadores, tema que no desarrollaremos aquí por cuestiones de espacio. 
en aquellos mundos antiguos, diferentes en muchas maneras, eran tan (o tan poco) inteligentes como nosotros. En las palabras de Barry Kemp,

"En el siglo XX, la acumulación de conocimientos nos ha proporcionado una ventaja sobre nuestros predecesores en lo que se refiere a la tecnología y a las diversas facultades mentales mediante las cuales podemos explorar el universo y generar una multiplicidad de imágenes lógicas. Pero no hemos de confundirlo con una mayor inteligencia. Inteligencia no equivale a conocimientos, sino a la facultad de dar una configuración lógica a los conocimientos que se tienen" (Kemp, 1992 [1989]: 8).

Por otro lado, los esfuerzos educativos deben orientarse a construir una nueva visión sobre la cultura e historia de las comunidades de aldea y los grupos nómadas pastoriles que rompa con estereotipos anquilosados y dicotomías simplistas y que reconozca la variedad de sus formas de organización sociopolítica y cultural, ubicando sus historias al lado de las historias de los centros urbanos y las sociedades estatales con las que han coexistido durante milenios y buscando comprender los complejos y múltiples entrelazamientos, intercambios y vinculaciones entre ellas (Silva Castillo, 1982, 2004; Briant, 1982; Schwatrz, 2006 [1995]; Saidel \& Van Der Steen, 2007; Szuchman, 2009; Tebes, 2012). Con este fin, los profesores debemos poder transmitir a nuestros estudiantes -como han puesto de manifiesto algunas líneas recientes de estudio sobre la política en las sociedades antiguas- el hecho de que ciertos pueblos no hayan desarrollado, o no hayan conservado, prácticas políticas coercitivas y/o instituciones centralizadas, y eso no se debió a una falla en su proceso evolutivo, sino a la clara presencia de una lógica de organización sociopolítica que impide -o rechaza- la emergencia de principios sociales asociados a la estatalidad. En igual sentido, el terreno empírico muestra que dos de los caracteres más sobresalientes de algunos de los grupos no estatales del antiguo Oriente son, por un lado, su notable aptitud de vincularse con las agencias estatales y permanecer de alguna forma fuera de éstas y, por otro, su tránsito exitoso de formas de organización centralizadas a otras no centralizadas según las circunstancias. De esta forma, es preciso mostrar a los estudiantes las estrategias que posibilitan a este tipo de poblaciones disminuir, anular o-inclusive-impedir la incidencia de la acumulación de poder (Gayubas, 2014).

A su vez, combinando perspectivas disciplinarias de la historia, la arqueología y la antropología para intentar desentrañar las complejas dinámicas de estas sociedades, se ha subrayado que las monarquías -esto es, formas estatales sumamente jerarquizadas y presididas por un poderoso rey, emperador o monarca- difícilmente agotan las formas de liderazgo político existentes en el mundo antiguo. Por el contrario, han existido otros regímenes políticos que se correspondían con otras lógicas sociales y ocupaban un espacio de singular relevancia (con anterioridad a la aparición de los Estados, pero también conviviendo con ellos de modos independientes o subordinados) a 
pesar de que, durante mucho tiempo, permanecieron invisibilizadas y/o estereotipadas. Se trataba de formas de jefatura relacionadas con el predominio del parentesco como lógica de organización social, o aquellas asociadas a las dinámicas de patronazgo, que expresan otro tipo de vínculos políticos que tal vez se identifican de modo más tenue pero que son igualmente relevantes para comprender las múltiples modalidades de lo social en aquel mundo antiguo (Campagno, 2009). A ello es preciso agregar los esfuerzos teóricos por precisar los conceptos de "ciudad-Estado", "Estados regionales" e "imperios" que pueden ser empleados para analizar las dinámicas de sociedades estatales que, si bien comparten algunas características, la lógica de sus prácticas pueden diferir en magnitud e incidencia (Di Bennardis, 2014). En el mismo sentido, las interpretaciones recientes acerca de las modalidades que adquirieron las relaciones entre los Estados del Cercano Oriente antiguo y las sociedades que habitaban sus periferias proponen que la pluralidad de sistemas sociopolíticos y culturales se encuentran, además, estrechamente relacionadas con la existencia de concepciones políticas particulares y con las complejas ontologías locales (Flammini, 2009; Pfoh, 2014).

De ese modo, más que como un conjunto de elementos inmutables en el tiempo y en el espacio, debemos procurar que los estudiantes comprendan a las tradiciones culturales que caracterizan a las sociedades del Cercano Oriente como una peculiar corriente de elementos, concepciones y prácticas en continua reconfiguración y con notables particularidades. En consecuencia, podrán incorporar una definición de cultura que les posibilite interpretar, de manera situada, un acervo material e intelectual creado, compartido, transmitido y modificado socialmente, compuesto por objetos, representaciones y formas de acción, en el cual se desarrollan ideas y pautas de conducta con que los miembros de una sociedad hacen frente individual o colectivamente, de manera mental o exteriorizada, a las distintas situaciones que se les presentan en la vida. No se trata, por tanto, de que vuelvan a la conceptualización de cultura como un mero conjunto cristalizado y uniforme de materiales y expresiones sociales que se transmiten de generación en generación, sino que sepan emplearla como una verdadera herramienta conceptual a la hora de explicar la forma propia que tiene una sociedad para responder intelectualmente ante cualquier circunstancia. Esta definición de cultura resulta muy operativa para "ver las sociedades y las civilizaciones del pasado por lo que realmente fueron: soluciones a los problemas de la existencia individual y colectiva que podemos sumar a la diversidad de soluciones manifiestas en el mundo contemporáneo" (Kemp, 1992 [1989]: 13).

Consideramos que es una conceptualización muy adecuada para nuestras prácticas de enseñanza puesto que también induce a que los estudiantes comprendan que sobre las culturas de los Estados y comunidades del Cercano Oriente se levantaron tradiciones locales y regionales, derivadas de particula- 
ridades ecológicas, políticas, étnicas, culturales e históricas propias de radios más reducidos. Y sobre las tradiciones locales y regionales se extendieron fuerzas de otra naturaleza, aunque nuevamente generalizadoras, generadas por sociedades que por distintos motivos tuvieron una influencia decisiva y aparentemente uniformadora en épocas determinadas y sobre amplias extensiones del Cercano Oriente. Sin embargo, las sociedades difundieron bienes, creencias, instituciones, conocimientos, estilos y modas; pero también implantaron sistemas, y no siempre para establecer relaciones simétricas sobre los pueblos incluidos en su radio de influencia. Por el contrario, las sociedades que ingresaban en sus sistemas de dominación y explotación tenían que responder a los papeles específicos que les asignaban en el nuevo orden sociopolítico, económico e ideológico introducido. Con frecuencia, los intentos de "globalización", breves algunos, prolongados otros, produjeron cambios decisivos en las sociedades anexadas en algunos casos y en otros inhibieron ciertos procesos, propiciando no solo semejanzas, sino también diferencias, complejizando aún más el escenario histórico de Oriente.

Poner en práctica estas posturas en nuestras aulas posibilitará que los estudiantes puedan acercarse mucho más a las realidades socioculturales históricas que intentamos enseñar y -por este medio-su capacidad de apelar a una mirada más compleja y que incorpore una perspectiva pluridisciplinar de los problemas sociohistóricos se multiplicará de manera significativa.

\section{Conclusiones}

La historia del antiguo Cercano Oriente ha sido largamente asociada, dentro de la historiografía, pero también dentro del campo de la enseñanza de la Historia en las instituciones escolares, al estudio de las primeras formas de organización en relación al trabajo, la distribución del excedente, la jerarquización social y la legitimación a través del culto y de los sistemas de creencias. Sin embargo, como creemos haber demostrado, la enseñanza de esta temática constituye uno de los tantos escenarios sociohistóricos que ofrece la posibilidad de abordar un conjunto de problemas teóricos e históricos sobre los que existen varias proposiciones del sentido común, producto de la vigencia de diferentes estereotipos historiográficos y antropológicos en el campo escolar que es preciso poner en discusión, por lo que los estudiantes puedan entrenar su espíritu crítico y, de ese modo, participar en la construcción de una concepción compleja y transformadora del conocimiento de la realidad social.

En efecto, se trata de una temática que brinda un terreno fructífero para el análisis diacrónico, sincrónico y comparativo, ya que su tratamiento conlleva no solo la posibilidad de identificar semejanzas y diferencias entre diversas situaciones históricas cercanas en términos conceptuales aunque no necesariamente contemporáneas en tiempo y espacio, sino también la 
oportunidad de establecer cambios y continuidades conforme a las múltiples conexiones que resultan de la ecuación pasado-presente y viceversa. $Y$ en tal dirección, la problematización de los sentidos conceptuales con que se consideran las dimensiones del tiempo, del espacio y de la cultura aparece como un paso fundamental en el camino de la construcción conjunta, entre docente y estudiantes, de conocimientos empíricamente fundados, teórica y metodológicamente armados y socialmente válidos de aquel cúmulo de experiencias socioculturales resultantes del complejo dinamismo histórico protagonizado por los antiguos pueblos del Próximo Oriente.

Si los profesores del área de Ciencias Sociales comienzan a entrenar a sus estudiantes en este tipo de procedimientos, con regularidad y de modo progresivo, habrán sabido formarlos en un modo de pensar caracterizado por la precisión, la severidad y el rigor a la hora de sostener argumentos y encontrar soluciones para los múltiples problemas que enfrenta la sociedad de la que forman parte.

\section{Referencias bibliográficas}

\section{a) Artículos}

Al-Otaibi, F. (2006). "Towards a Contrapuntal Reading of History: Orientalism and the Ancient Near East", en Journal of King Saud University. Science \& Arts, vol. 19, № 2, pp. 55-66.

Bahrani, Z. (1998). "Conjuring Mesopotamia: imaginative geography and a world past", en Meskell, L. (ed.). Archaeology under fire: Nationalism, politics and heritage in the Eastern Mediterranean and Middle East. New York: Routledge.

Campagno, M. (2004). "Próximos y Distantes: Egipto y África, del Período Predinástico al Reino Antiguo", en Flammini, R. (comp.), Aproximación al Antiguo Egipto. Buenos Aires: Editorial de la Universidad Católica Argentina.

Campagno, M. (2009). "Tres modos de existencia política: jefatura, patronazgo y Estado", en Campagno, M. (ed.), Parentesco, patronazgo y Estado en las sociedades antiguas. Buenos Aires: Facultad de Filosofía y Letras, Universidad de Buenos Aires.

Castellán, A. (1958). "Proposiciones para un análisis crítico del problema de la periodización histórica", en Anales de Historia Antigua y Medieval, № 8, pp.7-48.

De Bernardi, C. I. (1987). "Algunas reflexiones sobre los estudios de Historia Antigua Oriental", en Anuario de la Escuela de Historia (UNR) 12: 525-530.

De Bernardi, C. (2001). "Victimización, tolerancia, segregación. Las relaciones humanas en la Mesopotamia antigua", en Claroscuro. Revista del CEDCU, № 1, pp. 181-206. 
De Bernardi, C. I. y Ravenna, E. (2006). "'Orientalism' in Latin American Prospect", en Regalzi, G. (ed.) Mutuare, interpretare, tradurre: storie di culture a confronto. Atti del $2^{\circ}$ Incontro «Orientalisti» (Roma, 11-13 dicembre 2002). Roma: Università degli Studi «La Sapienza».

De Bernardi, C. y Silva Castillo, J. (2006). "Diversidad étnica, integración o victimización en la Meopotamia del III milenio a. C.", en De Bernardi, C. y Silva Castillo, J. C. (comps.), El Cercano Oriente Antiguo. Nuevas miradas a viejos problemas. México D. F.: El Colegio de México/Universidad Nacional de Rosario.

Di Bennardis, C. (2010). "La vivencia de la diversidad en las sociedades antiguas. Estado y comunidades: imposición y resistencia. Mesopotamia entre el III y II milenios a. C.", en Koldorf, A. E. (comp.), Multiculturalismo y diversidad. Un debate actual. Rosario: Prohistoria Ediciones.

Di Bennardis, C. (2014). "La centralización del poder político y el Estado en las sociedades antiguo-orientales: reflexiones sobre teorías e interpretaciones", en Di Bennardis, C; Milevski, I. y Ravenna, E. (eds.), Diversidad de formaciones políticas en Mesopotamia y el Cercano Oriente. Organización interna y relaciones interregionales en la Edad del Bronce. Barcelona: Institut del Pròxim Orient Antic, Universitat de Barcelona.

Di Bennardis, C., D'Agostino, F., Silva Castillo, J. y Milevski, I. (2010): "Relaciones centro urbano-periferia en la Mesopotamia Antigua y Zonas Contiguas del Cercano Oriente", en Rivista degli Studi Orientali, Vol. 83, № 1-4, pp. 10-229.

Flammini, R. (2005). "El antiguo Estado egipcio como alteridad: cosmovisión, discurso y prácticas sociales (ca. 3000-1800 a. C.)", en Iberia. Revista de la Antigüedad 8: 9-26.

Flammini, R. (2009). "Consideraciones sobre los vínculos sociales en el Levante Septentrional durante el Bronce Medio IIA-B", en Campagno, M. (ed.), Parentesco, patronazgo y Estado en las sociedades antiguas. Buenos Aires: Facultad de Filosofía y Letras, Universidad de Buenos Aires, 2009.

Gayubas, A. (2014). "Pierre Clastres y la guerra en el valle del Nilo preestatal", en Campagno, M. (ed.), Pierre Clastres y las sociedades antiguas. Buenos Aires: Miño y Dávila Editores.

Gómez Espelosín, F. (2004). "La Odisea y la invención del bárbaro 'avant la lettre'", en Remesal Rodríguez, J., Simón, F. M. y Pina Polo, F. (coords.), Vivir en tierra extraña. Emigración e integración cultural en el mundo antiguo. Zaragoza: Universidad de Barcelona.

González, M. L y Porta. L. G. (1997). "Periodización y Modernidad. Una problematización desde los procedimientos de enseñanza", en Clío \& Asociados. La historia enseñada, № 2, pp. 49-57. 
Guarinello, N. L. (2003): "Uma morfología da História: as formas da História Antiga", en Politeia. História e Sociedade, Vol. 3, № 1, pp. 41-61.

Larsen, M. T. (1987). "Orientalism and the Ancient Near East", en Culture and History, Vol. 2, pp. 96-115.

Liverani, M. (1999). "Ancient Near Eastern History: from Eurocentrism to an "Open" World", en Isimu. Revista sobre Oriente Próximo y Egipto en la antigüedad, Vol. 2, pp. 3-9.

Liverani, M. (2003). "La storia orientale antica nei nuovi programmi scolastici", en De Gerloni, B. (ed.), La storia fra ricerca e didattica. Milano: Franco Angeli Editore.

Megill, A. (1993). "Relatando el pasado: 'descripción', explicación y narrativa en la historiografía", en Historia Social, Vol. 16, pp. 71-96.

Murphy, S. B. (comp.) (2006). Repensando Oriente-Occidente. Buenos Aires: Oficina de Publicaciones de la Facultad de Filosofía y Letras, Universidad de Buenos Aires.

Murphy, S. B. (2013). "La enseñanza universitaria de los estudios del Cercano Oriente Afrosiático y la historiografía de la alteridad", en Pasado Por-Venir 7 (7): 175-189.

Pfoh, E. (2007). "¿Por qué enseñar historia antigua? Hacia una pedagogía de la tolerancia", en Cambios y Continuidades, № 6, pp. 185-192.

Pfoh, E. (2014). "Pierre Clastres y la antropología política de la antigua Palestina", en Campagno, M. (ed.), Pierre Clastres y las sociedades antiguas. Buenos Aires: Miño y Dávila Editores.

Schwartz, G. (2006 [1995]). "Pastoral Nomadism in Ancient Western Asia", en Sasson, J. M. (ed.), Civilizations of Ancient Near East. Massachusetts: Hendrikson Publishers.

Scheffler, T. (2003). "'Fertile crescent', 'Orient', 'Middle East': the changing mental maps of Southwest Asia", en European Review of History, Vol. 10, Nㅜ2, pp. 253-272.

Silva Castillo, C. (2004). "Nomadism through the ages", en Snell, D. (ed.), A Companion to the Ancient Near East. Oxford: Blackwell.

Van de Mieroop, R. (2004). "Economic Theories and the Ancient Near East", en Rollinger, R. y Christoph, U. (eds.), Commerce and Monetary Systems in the Ancient World. Means of Transmission and Cultural Interaction. Stuttgart: Franz Steiner Verlag.

West, M. L. (2006 [1995]). "Ancient Near Eastern myths in classical Greek religious thought", en Sasson, J. M. (ed.), Civilizations of Ancient Near East. Massachusetts: Hendrikson Publishers. 


\section{b) Libros}

Adams, C. y Roy, J. (eds.) (2007). Travel, geography and culture in ancient Greece and the Near East. Oxford: Oxbow.

Amin, S. (1989). El eurocentrismo. Crítica de una ideología. México D. F.: Siglo XXI Editores.

Aubet, M. E. (2007). Comercio y colonialismo en el Próximo Oriente Antiguo. Barcelona: Bellaterra.

Bernal, M. (1993 [1987]). Atenea negra. Las raíces afroasiáticas de la civilización clásica. La invención de la antigua Grecia, 1785-1985. Barcelona: Crítica.

Bloch, M. (2001 [1944]). Apología para la historia o el oficio de historiador. Edición anotada por Étienne Bloch. México: Siglo XXI Editores.

Breasted, J. H. (1916). Ancient times, a history of the early world. An introduction to the study of ancient history and the career of early man. Boston: Ginn.

Briant, P. (1982). État et pasteurs au Moyen-Orient ancien. París: Édition de la Maison des Sciences de l'Homme.

Burkert, W. (2002 [1999]). De Homero a los magos. La tradición oriental en la cultura griega. Barcelona: El Acantilado.

Burkert, W. (2005 [1987]). Cultos mistéricos antiguos. Madrid: Trotta.

Campagno, M. (2002). De los jefes-parientes a los reyes-dioses. Surgimiento y consolidación del Estado en el Antiguo Egipto. Barcelona: Aula AEgyptiaca.

Castellán, A. (1984). Tiempo e Historiografía. Buenos Aires: Biblos.

Charpin, D. y Joannes, F. (eds.) (1992). La circulation des biens, des personnes et des idées dans le Proche-Orient ancien. París: Editions Recherche sur les Civilisations-ERC/ADPF.

Chérif, M. (2007). El Islam y Occidente. Encuentro con Jacques Derrida. Buenos Aires: Nueva Visión.

Chesneaux, J. (2005 [1976]). ¿Hacemos tabla rasa del pasado? A propósito de la historia y los historiadores. México D. F.: Siglo XXI Editores.

Cervelló Autuori, J. (1996). Egipto y África. Origen de la civilización y la monarquía faraónicas en su contexto africano. Sabadell: Editorial Ausa, 1996.

Cervelló Autuori, J., Campagno, M. y Díaz de Cerio, M. (eds.) (2001): África Antigua. El Antiguo Egipto, una civilización africana. Barcelona: Aula AEgyptiaca.

Daneri Rodrigo, A. (ed.) (2001). Relaciones de intercambio entre Egipto y el Mediterráneo Oriental (IV-I Milenio A. C.). Buenos Aires: Biblos. 
Daneri Rodrigo, A. y Campagno, M. (eds.) (2004). Antiguos contactos. Relaciones de intercambio entre Egipto y sus periferias. Buenos Aires: Instituto de Historia Antigua Oriental «Dr. Abraham Rosenvasser», Facultad de Filosofía y Letras de la Universidad de Buenos Aires.

Djait, H. (1990): Europa y el Islam. Madrid: Libertarias.

Eco, U., Camdessus, M., Daniel, J. y Riccardi, A. (2005 [2003]). Islam y Occidente. Reflexiones para la convivencia. Buenos Aires: Sudamericana.

Foucault, M. (2013 [1971]). El orden del discurso. México: Tusquets.

Goody, J. (1996). L'Orient en Occident. Paris: Seuil, 1996.

Gouldner, A. W. (1979 [1970]). La crisis de la sociología occidental. Buenos Aires: Editorial Amarrortu.

Guarinello, N. L. (2013). História Antiga. São Paulo: Contexto.

Hartog, F. (1999 [1996]). Memoria de Ulises. Buenos Aires: Fondo de Cultura Económica.

Hartog, F. (2002 [1980]). El espejo de Heródoto. Buenos Aires: Fondo de Cultura Económica.

Hobson, J. (2006 [2004]). Los orígenes orientales de las civilizaciones de Occidente. Barcelona: Crítica.

Huntington, S. (2004 [1996]). El choque de las civilizaciones y la reconfiguración del orden mundial. Buenos Aires: Paidós.

Kemp, B. (1992 1989). El Antiguo Egipto. Anatomía de una civilización. Barcelona: Crítica.

Kuhrt, A. (2014 [1995]). El Oriente Próximo en la Antigüedad, c. 3000-330 a. C. Vol. 1. Barcelona: Crítica.

Lockman, Z. (2004). Contending Visions of the Middle East. The History and the Politics of Orientalism. Cambridge: Cambridge University Press.

Liverani, M. (2012 [1991]). El Antiguo Oriente. Historia, sociedad, economía. Barcelona, Crítica.

Liverani, M. (2003 [2001]). Relaciones internacionales en el Próximo Oriente antiguo, 1600-1100 a. C. Barcelona: Bellaterra.

O'Connor, D. y Quirke, S. (eds.) (2003): Mysterious lands. Encounters with Ancient Egypt. London: UCL Press.

Polanyi, K., Arensberg, C. M. y Pearson, H. W. (1976 [1957]): Comercio y mercado en los Imperios Antiguos. Barcelona: Labor. 
Preiswerk, R. y Perrot, D. (1979 [1975]). Etnocentrismo e Historia. América indígena, África y Asia en la visión distorsionada de la cultura occidental. México D. F.: Nueva Imagen.

Redman, C. L. (1990 [1978]). Los orígenes de la civilización. Desde los primeros agricultores hasta la sociedad urbana en el Próximo Oriente. Barcelona: Crítica.

Rollinger, R. y Christoph, U. (eds.) (2004). Commerce and Monetary Systems in the Ancient World. Means of Transmission and Cultural Interaction. Stuttgart: Franz Steiner Verlag.

Romero, J. L. (2008 [1988]). La vida histórica. Buenos Aires: Siglo XXI Editores.

Rowlands, M., Larsen, M. y Kristiansen, K. (eds.) (1987). Centre and Periphery in the Ancient World. Cambridge: Cambridge University Press.

Said, E. (1990 [1978]). Orientalismo. Barcelona: Libertarias.

Saidel, B. A. y Van der Steen, E. J. (eds.) (2007). On the Fringe of Society: Archaeological and Ethnoarchaeological Perspectives on Pastoral and Agricultural Societies. Londres: BAR International Series.

Sardar, Z. (2004 [1999]). Extraño Oriente. Historia de un prejuicio. Barcelona: Gedisa.

Silva Castillo, J. (comp.) (1982). Nómadas y pueblos sedentarios. México D. F.: El Colegio de México.

Smith, W. S. (1965). Interconnections in the ancient Near East. A study of study of relationships between the arts of Egypt, the Aegean, and Western Asia. New Haven: Yale University Press.

Szuchman, J. (2009) (ed.). Nomads, Tribes, and the State in the Ancient Near East. Chicago: The University of Chicago Press.

Tebes, J. M. (2012). Nómadas en la encrucijada. Sociedad, ideología y poder en los márgenes del Levante meridional durante el primer milenio a. C. Londres: BAR International Serie.

Veyne, P. (1984 [1978]). Cómo se escribe la historia. Foucault revoluciona la historia. Madrid: Alianza.

Wilkinson, T. J. (2003). Archaeological Landscapes of the Near East. Arizona: The University of Arizona Press. 